\title{
Urticária aquagênica familiar: relato de dois casos e revisão da literatura*
}

\section{Familial aquagenic urticaria: report of two cases and literature review}

\author{
Maria Bandeira de Melo Paiva Seize ${ }^{1}$ \\ Patrícia Karla de Souza ${ }^{3}$ \\ Silmara da Costa Pereira Cestari ${ }^{5}$
}

\author{
Mayra Ianhez ${ }^{2}$ \\ Osmar Rotta ${ }^{4}$
}

\begin{abstract}
Resumo: Urticária aquagênica é forma rara de urticária física caracterizada por aparecimento de urticas após o contato com água, independente da temperatura. Há poucos casos descritos de urticária aquagênica e, destes, somente cinco da forma familiar. Apresentamos o primeiro relato de urticária aquagênica familiar no Brasil, acometendo mãe e filha. Ambas apresentavam urticas, principalmente após banho de chuveiro, independentemente da temperatura da água. A mãe referia ter o quadro há quatro anos, e a filha, desde o nascimento. Para diagnóstico, foram realizados testes de provocação com água, com aparecimento de lesões em ambas, e testes com dermografômetro, com cubo de gelo envolvido em plástico e de provocação para urticária colinérgica, sem o aparecimento de lesões, excluindo assim outras formas de urticária física.

Palavras-chave: Água; Antagonistas dos receptores H1 de histamina; Prurido; Urticária

Abstract: Aquagenic urticaria is a rare form of physical urticaria, characterized by pruritic wheals that appear following contact with water, independently of its temperature. There are few reports of cases of aquagenic urticaria, and only five include the familial form. We present the first case of familial aquagenic urticaria in Brazil (mother and daughter). Both patients presented wheals following contact with water, especially when showering, regardless of its temperature. The mother reported onset of urticaria four years before and the daughter presented wheals since birth. For diagnostic purposes, they were submitted to a challenge test with water, and both subjects presented wheals, as well as to tests using ice cubes in plastic bag with dermographometer and challenge tests for cholinergic urticaria, with no appearance of lesions, excluding other forms of physical urticaria.

Keywords: Histamine H1 antagonists; Pruritus; Urticaria; Water
\end{abstract}

Recebido em 23.06.2008.

Aprovado pelo Conselho Editorial e aceito para publicação em 09.07.2009.

* Trabalho realizado na Universidade Federal de São Paulo (Unifesp) - Departamento de Dermatologia e ambulatório de dermatologia pediátrica - São Paulo (SP), Brasil.

Conflito de interesse: Nenhum / Conflict of interest: None

Suporte financeiro: Nenhum / Financial funding: None

Médica dermatologista pela SBD, especializanda em dermatologia pediátrica da Unifesp-EPM, mestranda em dermatologia pela Unifesp - São Paulo (SP), Brasil. Médica dermatologista pela SBD, especializanda em dermatologia pediátrica da Unifesp-EPM, mestranda em dermatologia pela Unifesp - São Paulo (SP), Brasil.

Especialista em dermatologia pela SBD, mestre em dermatologia pela Unifesp, médica colaboradora do Departamento de Dermatologia da Unifesp, responsável pelo ambulatório de dermatologia/urticária da Unifesp - São Paulo (SP), Brasil.

Especialista em dermatologia pela SBD, mestre em dermatologia pela Faculdade de Medicina da Universidade de São Paulo, doutor em dermatologia pela Unifesp-EPM, professor associado ao Departamento de Dermatologia da Unifesp, coordenador de extensão, vice-supervisor da residência e chefe do Departamento de Dermatologia da Unifesp - São Paulo (SP), Brasil.

Especialista em dermatologia pela SBD, mestre e doutora em dermatologia pela Universidade Federal de São Paulo-Escola Paulista de Medicina (UNIFESP-EPM),

professora adjunta do Departamento de Dermatologia da Unifesp - São Paulo (SP), Brasil. 


\section{INTRODUÇÃO}

A urticária aquagênica foi descrita pela primeira vez em 1964 por Shelley e Rawnsley. ${ }^{1}$ É uma forma rara de urticária física, caracterizada pela formação de lesões urticariformes perifoliculares após contato com água, independente da temperatura. As lesões medem de 2 a $3 \mathrm{~mm}$ de diâmetro, localizam-se preferencialmente no tronco e parte superior dos membros e podem durar de 10 a 50 minutos. ${ }^{1,2}$

Acomete mais frequentemente mulheres do que homens e em geral inicia-se na puberdade. ${ }^{1}$ A ocorrência em crianças é bastante incomum, ${ }^{3-7}$ o mesmo podendo ser dito para os casos familiares, pois a maioria se apresenta de maneira isolada. ${ }^{2-4}$

A urticária aquagênica pode estar associada a outros tipos de urticária física, como a urticária colinérgica, a causada por frio e o dermografismo. ${ }^{1,3}$ Para estabelecer o diagnóstico correto de urticária aquagênica é fundamental excluir outras formas de urticária física, sendo também necessário que o teste de provocação por água leve à formação de lesões urticariformes. ${ }^{8}$

Apresentamos dois casos de urticária aquagênica familiar, mãe e filha, que parecem ser os primeiros publicados de urticária aquagênica familiar no Brasil, onde há relato anterior de somente um caso de urticária aquagênica, em paciente adulto e sem história familiar da doença.' A paciente mais jovem é um dos poucos casos relatados de urticária aquagênica com início antes da puberdade, ${ }^{2,3,5,6}$ sendo provavelmente o primeiro com início logo após o nascimento.

\section{RELATO DOS CASOS}

CASO 1- Paciente do sexo feminino, branca, de 28 anos, relata aparecimento há quatro anos de urticas em torno de dez minutos após contato com água, principalmente com o banho de chuveiro, independente da temperatura. As lesões geralmente são puntiformes, acometem principalmente pescoço e tronco e duram de cinco a 20 minutos. Não relata aparecimento de lesões nas extremidades. $\mathrm{O}$ contato com altas e baixas temperaturas, na ausência de água, não reproduz as lesões. Não há história de antecedentes pessoais atópicos. Refere que pai, irmão e filha apresentam o mesmo quadro após contato com água. Não há história de uso prévio de anti-histamínicos ou outras medicações. Nega vertigem, palpitações ou cefaleia durante as crises. Ao exame físico a paciente não apresentava lesões.

Foram realizados testes de provocação no dorso com os seguintes resultados:

Dermografismo (realizado com dermografômetro $=4,0 \times 105 \mathrm{~Pa})$ - negativo.

Frio (aplicação de cubo de gelo envolto em filme plástico por 20 minutos) - negativo.

Teste para urticária colinérgica (calor e exercício físico) - negativo.
Teste de provocação aquagênica (aplicação de compressa embebida em água na temperatura corporal por 20 minutos) - positivo com o aparecimento de lesões urticariformes (Figura 1).

Após a realização dos testes citados foi feito o diagnóstico de urticária aquagênica e proposto o tratamento com hidroxizina. A paciente se recusou a fazer uso da medicação.

CASO 2 - Paciente do sexo feminino, branca, com um ano e sete meses, filha da paciente descrita no caso 1, apresentando urticas desde o nascimento, com início em cerca de dez minutos após contato com água, independente da temperatura. As lesões surgem principalmente após o banho de chuveiro ou banheira e, assim como no caso 1 , afetam principalmente o tronco e pescoço, não acometem as extremidades e duram de cinco a 20 minutos. Avô e tio maternos com história de lesões semelhantes. Ao exame físico, a paciente não apresentava lesões.

Foram realizados os mesmos testes de provocação descritos para a paciente do caso 1, e também foi feita imersão da criança em uma banheira com água na temperatura tépida. O teste de provocação por água foi positivo, com aparecimento de lesões urticariformes no tronco após esse teste. Os testes com dermografômetro, com cubo de gelo e de provocação para urticária colinérgica foram negativos.

Foi proposto o tratamento com hidroxizina, porém a mãe se recusou a fazer uso da medicação por saber que o medicamento não proporcionaria a cura da urticária aquagênica.

\section{DISCUSSÃO}

A urticária aquagênica manifesta-se pelo aparecimento de lesões urticariformes alguns minutos após o contato com a água de qualquer temperatura. 1 Estas duram cerca de meia hora e, na maior parte dos casos, não há outras manifestações concomitantes. Porém,

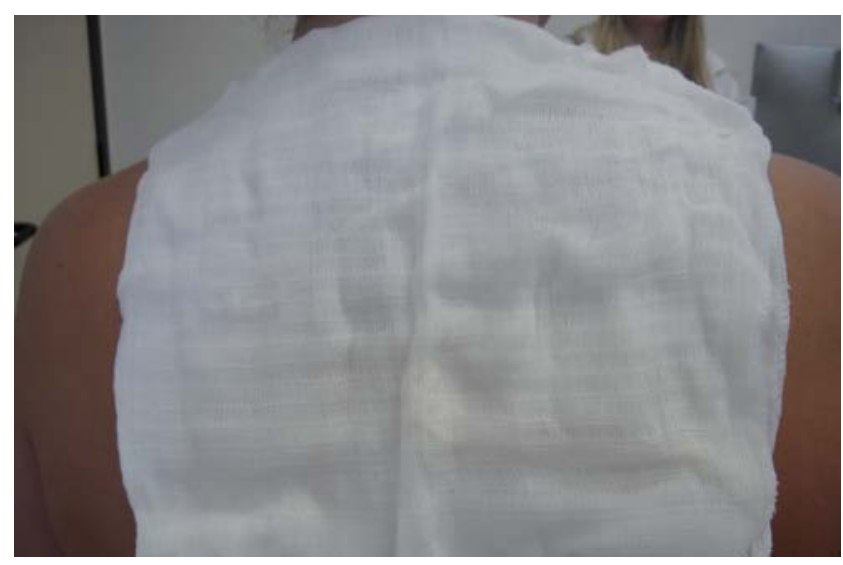

Figura 1: Paciente 1 - realização do teste de provocação com compressa embebida em água 
alguns casos podem ser acompanhados de dermografismo e outras manifestações extracutâneas, como cefaleia, broncoespasmo e angioedema. ${ }^{5,10}$

Nos dois casos descritos, as manifestações clínicas apresentadas pelas pacientes são semelhantes às de outros casos de urticária aquagênica publicados na literatura. ${ }^{10}$

Essa forma de urticária se manifesta, com maior frequência, de forma isolada. A forma familiar, como a descrita nos casos apresentados, é bastante rara. Até o presente, segundo pesquisa realizada nas bases de dados Pubmed, Lilacs, Medline Scielo e Biblioteca Cochrane, só foram encontrados cerca de 30 casos de urticária aquagênica publicados, sendo menos de 10 destes de ocorrência familiar. ${ }^{10} \mathrm{O}$ primeiro caso familiar foi relatado em 1967 por Tromovitch, que descreveu o quadro em dois irmãos, sendo uma do sexo feminino com início do quadro aos nove anos de idade e um do sexo masculino. ${ }^{2}$ Nos poucos casos publicados com a forma familiar, a maioria dos pacientes são do sexo feminino, ${ }^{3,4,10}$ assim como as pacientes dos casos descritos acima.

As pacientes aqui relatadas parecem ser os primeiros casos de urticária aquagênica familiar publicados no Brasil, pois, após realizarmos pesquisa nas bases de dados citadas acima, encontramos somente um caso descrito por Medeiros, publicado em 1996, sendo, porém, adulto e sem história familiar da doença.'

A urticária aquagênica em geral se inicia na puberdade, sendo o início da doença na infância bastante raro, havendo poucos relatos na literatura. ${ }^{2,47,10}$

Segundo a literatura, na forma infantil da urticária aquagênica, ambos os sexos parecem ser acometidos na mesma proporção. A forma familiar com ocorrência na infância foi encontrada em três dos casos publicados, sendo a maioria dos pacientes com forma familiar e infantil do sexo feminino, como a descrita por nós no caso 2. Tal paciente também é uma das mais jovens já pesquisadas na literatura e parece ser o primeiro caso de urticária aquagênica em crianças publicado no Brasil.

A patogênese dessa forma de urticária não está completamente esclarecida, e vários mecanismos foram propostos. Em 1964, Shelley e Rawnsley sugeriram que a reação da água com componentes do estrato córneo ou das glândulas sebáceas formaria uma substância tóxica que seria absorvida pela pele, ocasionando a degranulação de mastócitos perifoliculares e liberação de histamina com consequente formação de urticas. ${ }^{1}$ Czarnetzki et al. ${ }^{11}$ sugeriram haver um antígeno hidrossolúvel na epiderme que em contato com a água se difundiria para a derme, causando liberação de histamina pelos mastócitos. Esta parece ser mediador químico importante na patogênese da urticária aquagênica. Outros mediadores como acetilcolina, serotonina e bradicinina possivelmente também estão envolvidos na patogênese da urticária aquagênica. ${ }^{5,9,12}$

Para o diagnóstico correto da doença há dois critérios importantes: ${ }^{7}$ excluir outras causas de urticária física e obter teste de provocação com água positivo. Esse teste é realizado com a aplicação de compressa embebida em água a $37{ }^{\circ} \mathrm{C}$ em contato com a pele, preferencialmente no tronco, por 20 minutos. Nos pacientes com urticária aquagênica o teste é seguido pelo aparecimento de lesões urticariformes, confirmando assim o diagnóstico. ${ }^{2,11,13}$

É importante fazer o diagnóstico diferencial com urticária colinérgica e urticária ao frio. ${ }^{13} \mathrm{Na}$ urticária colinérgica há formação de urticas quando ocorre o aumento da temperatura corporal. ${ }^{2} \mathrm{Na}$ urticária ao frio, há formação de urticas após exposição ao frio. ${ }^{1,2}$ $\mathrm{Na}$ urticária aquagênica o teste de provocação com gelo é negativo, excluindo assim a urticária ao frio. Tampouco surgem lesões somente com o aumento da temperatura corporal, como ocorre com a urticária colinérgica.

As pacientes dos casos 1 e 2 aqui relatados apresentaram formação de urticas após contato com a água e obtiveram resultado negativo nos testes de provocação por gelo, pelo dermografômetro e nos testes de provocação para urticária colinérgica, reforçando o diagnóstico de urticária aquagênica familiar (mãe e filha).

Talvez por sua semelhança com outras formas de urticária crônica, o diagnóstico de urticária aquagênica deixa de ser feito com maior frequência. Reforçamos a importância de anamnese e avaliação dermatológica minuciosas, com realização dos testes de provocação necessários para chegar ao diagnóstico correto.

Para o tratamento da urticária aquagênica os anti-histamínicos como hidroxizina e cetirizina são atualmente as medicações de escolha, porém há casos refratários a essas drogas. Também podem ser usados anticolinérgicos como a escopolamina. ${ }^{14}$ Os emolientes não são eficazes em controlar a urticária, porem há relato de melhora dos sintomas com cremes de barreira antes da exposição à água. ${ }^{15}$

A relevância dos casos aqui relatados se baseia no fato de serem os primeiros casos de urticária aquagênica com forma familiar descritos no Brasil e de a paciente do caso 2 ser a mais jovem já pesquisada na literatura e o único caso com início das lesões logo após o nascimento. ${ }^{2,4,7,10}$ 


\section{REFERÊNCIAS}

1 Shelley WB, Rawnsley HM. Aquagenic urticaria. JAMA. 1964;189:119-22.

2 Tromovitch TA. Urticaria from contact with water. Calif Med. 1967;106:400-1.

3 Treudler R, Tebbe B, Steinhoff M, Orfanos CE. Familial aquagenic urticária associated with familial lactose intolerance. J Am Acad Dermatol. 2002;47:611-3.

4 Bonnetblanc JM, Andieu-Pfahl F, Meraud JP, Roux J. Familial aquagenic urticaria. Dermatológica. 1979; 158:468-70.

5 Frances AM, Fiorenza G, Frances RJ. Aquagenic urticária: report of a case. Allergy Asthma Proc. 2004;25:195-7.

6 Wasserman D, Preminger A, Zlotogorski A. Aquagenic urticaria in a child. Pediatr Dermatol. 1994;11:29-30.

7 Parker RK, Crowe MJ, Guin JD. Aquagenic urticaria. Cutis. 1992;50:283-4.

8 Black AK, Lawlon F, Greaves MW. Consensus meeting on the definition of physical urticarias and urticarial vasculitis. Clin Exp Dermatol. 1996;21:424-6.

9 Medeiros M Jr. Aquegenic urticaria. J Investig Allergol Clin Immunol. 1996;6:63-4.

10 Luong KV, Nguyen LT. Aquagenic urticaria: report of a case and review of the literature. Ann Allergy Asthma Immunol. 1998;80:483-5.

11 Tkach JR. Aquagenic urticaria. Cutis. 1981;28:454-63.
12 Sibbad RG, Black AK, Eady RA, James M, Greaves MW. Aquagenic urticaria: evidence of cholinergic and histaminergic basis. Br J Dermatol. 1981;105:297-302.

13 Black AK, Lawlon F, Greaves MW. Consensus meeting on the definition of physical urticarias and urticarial vasculitis. Clin Exp Dermatol. 1996;21:424-6.

14 Baptist AP, Baldwin JL. Aquagenic urticaria with extracutaneous manifestations. Allergy Asthma Proc. 2005; 26: 217-20.

15 Bayle P, Gadroy A, Messer L, Bazex J. Localized aquagenic urticaria: efficacy of a barrier cream. Contact Dermatitis. 2003; $49: 158-72$.

\author{
ENDEREÇO PARA CORRESPONDÊNCIA / MAILING ADDRESS: \\ Maria Bandeira de Melo Paiva Seize \\ Alameda Joaquim Eugenio de Lima, 1.094 - ap. 82 \\ Jardim Paulista \\ 01403002 São Paulo SP \\ E-mail:maria.p.seize@botmail.com \\ Tel.:/Fax: 5511 3887-2245 / 8315-1488 / 3088-9000
}

Como citar este artigo/How to cite this article: Seize MBMP, Ianhez M, Souza PK, Rotta O, Cestari SCP. Urticária aquagênica familiar: relato de dois casos e revisão da literatura. An Bras Dermatol. 2009;84(5):530-3. 